\title{
Patoloji Laboratuvarında Örnek Gönderimi ve Kayıt Esnasında Karşılaşılan Preanalitik Hataların Değerlendirilmesi
}

\author{
Zeynep Tosuner@
}

Bezmialem Vakıf Üniversitesi, Patoloji, İstanbul, Türkiye

Zeynep Tosuner, Uzm. Dr.

İletişim:

Uzm. Dr. Zeynep Tosuner

Bezmialem Vakıf Üniversitesi, Patoloji, Istanbul, Türkiye

Tel: +905327366951

E-Posta: zeyneptosuner@yahoo.com.tr
ÖZET

Amaç: Patoloji laboratuvarında örnek kabul ve red kriterleri Sağılı Bakanlığı ve Patoloji Dernekleri Federasyonu tarafından belirlenmiştir. Örnek gönderilirken yapılan bir hata tüm patolojik işleyişi ve hasta yönetimini etkileyebilmektedir. Bu çalışmanın amacı preanalitik süreçte yapılan hataların niteliklerini belirlemek ve bu hataların kaynaklarını ortaya koymaktır.

Yöntemler: Patoloji Anabilim dalında 2015-2017 yılları arasında red formları ile hata bildirim tutanakları incelenmiş olup preanalitik dönemde örnek gönderim ve kayıt işlemleri sırasında yapılan hatalar belirlenmiştir. Bulgular: Bölüm içi kaynaklı, yanlış barkod verilmesi ve hatalı işlem kaydını içeren toplam 24 hata söz konusudur. Bölüm dışı hatalar incelendiğinde toplam 49 hata tespit edilmiştir. Bu hatalar kimlik bilgisi-barkod hataları ve örnek bildirimi ile ilgili hatalardır. Bu hataların tamamı görevli Patoloji personeli tarafından fark edilerek düzeltilmeleri sağlanmıştır.

Sonuç: Patoloji bölümüne örnek gönderimi birçok klinik uzmanlık dalını ilgilendiren bir süreçtir. Patoloji kayıt personelinin ve örnek gönderen birimlerde çalışan personelin gönderim kuralları ve kabul-red kriterleri konusunda bilinçli olması preanalitik dönemdeki hataların önlenmesini sağlayabilir.

Anahtar sözcükler: Patoloji, preanalitik hata, örnek gönderimi

EVALUATION OF PREANALYTICAL PHASE ERRORS IN SPECIMEN COLLECTION AND DELIVERY IN PATHOLOGY LABORATORY

\section{ABSTRACT}

Objective: Specimen acceptance and rejection criteria are determined by the Turkish Ministry of Health and the Federation of Pathology Associations. An error occurring in specimen delivery can affect all the pathological operations and patient management. The purpose of this study is to determine the types of errors occurring in the preanalytical phase before sample accessioning and to reveal the sources of these errors.

Methods: Preanalytical identification and sample delivery errors that had been encountered between 2015-2017 in our pathology department were analysed.

Results: Twenty four intradepartmental errors concerning labeling and sample identification were recorded. A total of 49 extradepartmental errors including patient identity errors and failures occurring in the sample delivery phase were detected. All of these errors were noticed and corrected by staff working in the pathology laboratory.

Conclusion: A number of clinical departments are involved in specimen delivery to the pathology department. Pathology registry staff and the staff working in the sample sending units should be conscious of the specimen delivery rules and acceptance/rejection criteria in order to prevent the errors in the preanalytical period.

Keywords: Pathology, preanalytical error, specimen delivery
Gönderilme Tarihi : 24 Nisan 2018

Revizyon Tarihi : 24 Nisan 2018

Kabul Tarihi

: 06 MAyıs 2018 
$\mathbf{P}$ reanalitik evre ISO 15189:2012 Tıbbi laboratuvarlar-Kalite ve yeterlilik için özel şartlar standardı tarafından "klinisyenin isteğiyle başlayan, kronolojik olarak, test istemi, hastanın tanımlanması ve hazırlanması, birincil numunelerin alınması, laboratuvara ve laboratuvar içinde taşınmasını içeren, analiz işlemini başlamasıyla biten işlemler" olarak tanımlanmıştır $(1,2)$. Patoloji laboratuvarında hatalar preanalitik, analitik ve postanalitik evrelerde görülebilir. Preanalitik evrede hatalar patoloji bölümüne örnek gönderimi ve kayıt aşamasından makroskopik incelemeye kadarki süreçte meydana gelmektedir. Bu hataların çoğunluğu; örneklerin toplanması, taşınması, analiz için hazırlanması süreçlerinde olmaktadır.

Patoloji laboratuvarına örnek kabul işlemi esnasında örnekler istem formu ile birlikte gönderilmelidir. Bu form hastanın adı-soyadı, cinsiyeti, doğum tarihi, doğum yeri ve hastane protokol numarası içeren barkodun yanısıra örnek gönderen hekimin adı-soyadı, imzası, hastaya ait klinik bilgileri, önceki laboratuvar sonuçları, klinik ön tanı, doku ve örneğin hangi organdan alındığı, alınma yöntemi, cerrahi sınır ile ilgili bilgiler, alınma tarihi ve saatini içermelidir. Dokuların patoloji laboratuvarına transferi, dokunun uygun tespit solüsyonu içeren uygun transfer kabı içinde transfer için eğitimli bir personel tarafından sağlanmalıdır. Sağlık Bakanlığı ve Patoloji Dernekleri Federasyonu tarafından Patoloji Bölümü'ne gönderilen örneklerle ilgili olarak red kriterleri tanımlanmıştır. Örnekle birlikte Patoloji talep formunun bulunmaması, Patoloji değerlendirme talep formunda hastayı tanımlayan bilgilerin olmaması, isim, protokol, lokalizasyon bilgilerinin yanlış veya eksik olması, Patoloji talep formu ile örnek kabının üzerindeki bilgilerin eşleşmemesi, sitolojik inceleme veya konsültasyon için gelen onarılamayacak derecede kırılmış yayma preparatlar, talep edilen patolojik incelemenin laboratuvar tarafından uygulanamayacak olması red kriterleridir $(3,4)$. Örnek gönderimi, kabul ve kayıt esnasında oluşabilecek bir hata, bir sonraki aşama olan makroskopide fark edilebileceği gibi mikroskopik inceleme aşamasına dek fark edilmeyebilir. Bu durum hastanın tanısını ve tedavisini etkileyebilecek ciddi sonuçlar doğurabilir.
Bu çalışmanın amacı Bezmialem Vakıf Üniversitesi'nde 2015-2017 yılları arasında örnek gönderme ve kayıt esnasında gözlemlenen hataların ve bu hataların kaynaklarının belirlenmesidir.

\section{Materyal-metod}

Yılda ortalama 26000 biyopsi ve sitoloji vakasının değerlendirildiği Patoloji Anabilim dalında 2015-2017 yılları arasında red formları ile hata bildirim tutanakları incelenmiş olup preanalitik dönemde örnek gönderim ve kayıt işlemleri sırasında yapılan hatalar belirlenmiştir. Bu hatalar bölüm içi- kayıt sekreterliği veya bölüm dışı-gönderen birim, transfer görevlisi ya da hastanın kendisi kaynaklı olabilmektedir.

\section{Bulgular}

Bölüm içi hatalar incelendiğinde, toplam 24 hata söz konusudur. Dokuz hastaya kayıt görevlisi tarafından yanlış barkod verilmiş bu durum kayıt sonrasında makroskopi personeli tarafından fark edilerek çözümlenmiştir. On beş hastada ise hatalı işlem kaydı yapılmış bu hatalar mikroskobik değerlendirme esnasında çözümlenmiştir (Tablo 1).

Bölüm dışı hatalar incelendiğinde toplam 49 hata tespit edilmiştir. On yedi hastada kimlik bilgisi-barkod hataları izlenmiştir. Bu hastalardan 7'sinde hata kayıt personeli tarafından fark edilerek düzeltilmiş, diğer 10 vakada ise hatalar mikroskopik incelemeyi yapan doktor tarafından fark edilmiştir. Dört olguda kap içinde doku izlenmediği için örnekler red formu doldurularak gönderen birime geri gönderilmiştir. Bu olgularda klinik olarak gerekli görülmediğinden biyopsi alınmadığı, ancak önceden biyopsi için hazırlanan kapların yanlışlıkla Patoloji Bölümü'ne gönderildiği tespit edilmiştir. Bir olguda örneğin mikrobiyoloji laboratuvarına Patoloji istem formu ile gönderilmiş olduğu fark edilerek örnek gönderen birime red formu ile iade edilmiştir. Yedi olgu klinik bilgi eksikliği nedeniyle reddedilerek söz konusu kliniklere iade edilmiştir. Bu olgular klinik tarafından düzeltmeler yapılarak tekrar patolojiye gönderilmiştir. On beş olguda fiksatifsiz veya uygun olmayan fiksatif içinde gönderme hatası tespit edilmiştir. On üç hastaya ait doku örneği solüsyonsuz olarak, iki örnek

Tablo 1. Bölüm içi kaynakı hataların dağılımı, nitelikleri ve çözüm süreçleri

\begin{tabular}{lcc}
$\begin{array}{l}\text { Hata sayısı } \\
\text { Toplam:24 }\end{array}$ & Hatanın niteliği & $\begin{array}{c}\text { Hatanın fark edildiği ve } \\
\text { çözüldü̈̆̈̈ birim/Süreç }\end{array}$ \\
\hline 9 & Yanlış barkod & Makroskopi \\
15 & Hatalı işlem kaydı & Mikroskopik inceleme
\end{tabular}

Hatanın fark edilmesini
sağlayan durum


Tablo 2. Bölüm dışı kaynakıı hataların dağılımı, nitelikleri ve çözüm süreçleri

\begin{tabular}{|c|c|c|c|c|}
\hline $\begin{array}{l}\text { Hata Sayısı } \\
\text { Toplam: } 49\end{array}$ & Hatanın niteliği & $\begin{array}{l}\text { Kabul/ } \\
\text { Red Durumu }\end{array}$ & $\begin{array}{l}\text { Hatanın fark edildiği ve } \\
\text { çözüldüğü birim/Süreç }\end{array}$ & $\begin{array}{l}\text { Hatanın fark edilmesini sağlayan durum/ } \\
\text { Red nedeni, çözüm şekli }\end{array}$ \\
\hline 7 & Çapraz etiketleme & Red & Kayıt birimi & $\begin{array}{l}\text { Patoloji istem kağıdındaki kimlik bilgileri ile barkodun eşleşmemesi. } \\
\text { Hata fark edilerek çözümlenmesi için örnekler kliniğe geri gönderildi. }\end{array}$ \\
\hline 10 & $\begin{array}{l}\text { Hatalı/ } \\
\text { Çapraz etiketleme }\end{array}$ & Kabul & $\begin{array}{l}\text { Mikroskopik } \\
\text { inceleme }\end{array}$ & $\begin{array}{l}\text { Patoloji istem kağıdındaki kimlik bilgileri veya bilgisayar sistemindeki } \\
\text { bilgiler ile barkodun veya klinik bilgilerinin eşleşmemesi. Hata } \\
\text { mikroskopik incelemeyi yapan doktor tarafından fark edilerek doğru } \\
\text { raporların düzenlenmesi sağlandı. }\end{array}$ \\
\hline 4 & Kapta doku izlenmemesi & Red & Kayıt birimi & $\begin{array}{l}\text { Doku gönderim kabının boş olması. } \\
\text { Örnekler hata tespiti için kliniğe geri gönderildi. }\end{array}$ \\
\hline 1 & $\begin{array}{l}\text { Farklı departmana } \\
\text { gönderilecek doku gelmesi }\end{array}$ & Red & Kayıt birimi & $\begin{array}{l}\text { Patoloji istem kağıdında mikrobiyolojik inceleme ve } \\
\text { kültür isteminin belirtilmiş olması. Örnek mikrobiyolojiye yönlendirilmek } \\
\text { üzere kliniğe geri gönderildi. }\end{array}$ \\
\hline 7 & $\begin{array}{l}\text { İstem formunda } \\
\text { klinik bilgi eksikliği }\end{array}$ & Red & Kayıt birimi & $\begin{array}{l}\text { İstem formunda hastayı tanımlayan bilgilerin olmaması. } \\
\text { Örnekler kliniğe geri gönderildi. }\end{array}$ \\
\hline 20 & $\begin{array}{l}\text { Fiksatif/ Gönderim } \\
\text { Kabı ile ilgili hatalar }\end{array}$ & Kabul & Kayıt birimi & $\begin{array}{l}\text { Örnekler \%10'luk formole ve/veya uygun kaba alınmak üzere } \\
\text { makroskopi birimine yönlendirildi. }\end{array}$ \\
\hline
\end{tabular}

ise serum fizyolojik içinde gönderilmiştir. Solüsyonsuz örnekler makroskopi personeli tarafından uygun solüsyona alınmıştır. Hastanın kendisinin getirdiği bir örnekte transfer esnasında gönderim kabının kapağının açıldığı, kabın içinde olduğu poşetin içine formolün döküldüğü fark edilmiş, makroskopi personeli tarafından poşet içindeki doku uygun şekilde takibe alınmıştır. İki olguda örneğin ameliyat eldiveni içinde gönderildiği, 2 histerektomi materyalinin ise idrar kabı içinde gönderildiği tespit edilmiştir. Bu hataların tamamı görevli Patoloji personeli tarafından fark edilerek hataların düzeltilmesi sağlanmıştır (Tablo 2)

\section{Tartışma}

Laboratuvarda izlenen hataların \%80'inden fazlasının preanalitik faz hatalar olduğu ve bu hataların da insan kaynaklı olduğu bilinmektedir. En sık görülen preanalitik hatalardan biri kayıt hatalarıdır (5). Patoloji Bölümü'nde meydana gelen tüm preanalitik ve analitik faz hataları göz önüne alındığında bu hataların yine en büyük kısmının doku işleme alınmadan önce örneklerin toplanmasında meydana gelen hatalar olduğu dikkati çekmektedir (6). 417 patoloji bölümünden $1,004,115$ olgu üzerinde yapılan bir çalışmada kayıt ve işlem hatalarının \%6 oranında izlendiği bildirilmiştir. Örnek kayıt hatalarının \%77'sinde yanlış veya eksik klinik bilgi olduğu gözlenmiştir. Bu hataların \%40'ında hata, patolojide işlem girişi yapan personel veya histoloji personeli tarafından fark edilmiştir (7). Türkiye'de bir üniversite hastanesinde yapılan, preanalitik fazda spesimen reddinin sebeplerini araştıran bir çalışmada 1 yıl içinde 971,780 biyokimyasal spesimenin 26,070 'inin (\%2.7) laboratuvarın red kriterleri talimatı uyarınca reddedildiği gözlenmiştir. Bu laboratuvar örneklerinde en sık $(\% 55,8)$ reddedilme nedeni spesimende pıhtılaşma görülmesi olarak saptanmıştır. İkinci en sık reddedilme nedeni ise $(\% 29,3)$ yetersiz örnek olarak bildirilmiştir (8).

Çalışmamızda ise yer alan bölüm dışı kaynaklı 49 hatanın 24'ünde (\%48.9) klinik bilgi hatası veya eksikliği söz konusudur. Preanalitik hatalar incelendiğinde mikroskopik inceleme aşamasına kadar farkedilmeyen barkod hatalarının olabildiği görülmüştür. Örneğin aynı serviste yatan 2 hastanın barkodlarının çaprazlandığı bir durumda bilgisayar sistemindeki epikrizde klinik verilerin örtüşmemesi ile hata ortaya çıkmıştır. Bu durum mikroskopik incelemeyi yapan hekimin, söz konusu olabilecek hata riskleri ile ilgili olarak bilinçli ve dikkatli davranmasının sürecin yönetimi açısından son derece önemli olduğunu göstermektedir.

Klinikten gelen örneklerin kayıt işlemlerinin internet tabanlı bir veri sisteminden yapıldığı ve otomatik barkod sistemleri ile tanımlandığı bir bilgisayar yazılımının kullanımının preanalitik insan kaynaklı hataları önlediği de bildirilmiştir (9).

Bir biyopsi örneği rutin histolojik inceleme için Patoloji Bölümü'ne doku hacminin en az 5 katı kadar \%10'luk formol solüsyonu içerecek uygun bir transfer kabında gönderilmelidir (3).

Materyaller Patoloji laboratuvarına imza karşılığı ve kayıtla alınmalıdır. İstem kağıdı ve materyal kutusu üzerindeki kimlik uyumu, istem kağıdındaki bilgilerin yeterliliği, alınan dokunun uygun solüsyon ile gönderilip 
gönderilmediği kontrol edilmelidir. Aynı olguya ait birden fazla doku olduğunda lokalizasyonların istem kağıdında bulunması denetlenmelidir (10).

Örneklerin uygun fiksatif ile gönderilmemesi dokuda otolize ve optimal incelemenin yapılamamasına neden olabilir. Özellikle hafta sonuna denk gelen ameliyat materyallerinde bu durum daha fazla önem arz etmektedir. Biyopsi materyalinin fiksatifsiz veya az fiksatifle gönderildiği bir durum tespit edildiğinde doku yeterli fiksatifin içine konarak ertesi gün takip işlemine alınmalıdır. Raporda, değerlendirmenin yetersiz şartlarda yapıldığı belirtilmeli, görülebilen dokulardan mikroskopik tanımlama yapılmalı ve mümkün olduğunca hastanın tedavisi icin gerekli olan parametreler yazılmalıdır (11). Dokunun uygun kap içerisinde gönderilmemesi de dokunun şeklinin bozulmasına veya fikse olmamasına neden olabilir. Ameliyat eldiveni içinde veya kapağı sıkıca kapatılmamış halde parça gönderimi materyalin kaybı açısından risk taşımaktadır. Frozen inceleme ve immunfloresan için dokunun fiksatifsiz veya kurumasına engel olacak şekilde serum fizyolojik ile ıslatılmış halde gönderilmesi gerekmektedir. Bu dokuların yanlışıkla formolde gönderilmesi gerekli incelemenin yapılamamasına yol açmaktadır. Biyopsi örneklemesi bazı durumlarda hastada ciddi vital etkilere neden olabilecek invaziv bir süreçtir. Bu invaziv sürecin sonucu olarak alınan biyopsi örneklerinin gönderimindeki aksaklık parçanın değerlendirilemeyecek ölçüde bozulmasına veya parça kaybına ve dolayısıyla telafi edilemeyecek durumlara yol açabilir. Bu nedenle örneğin gönderimi esnasında da en az biyopsi alınırken olunduğu kadar hassas ve dikkatli davranılmalıdır. Hastaya ait klinik bilgiler de biyopsi değerlendirmesi için oldukça önemlidir. Örneğin mesane transüretral rezeksiyon (TUR) biyopsilerinde sistoskopik gözlemlerin ayrıntılı olarak belirtilmesi gereklidir. Mesane re-TUR biyopsi ve intravezikal Bacilius Calmette Guerin tedavisi sonrasında, mesanede birbirine oldukça benzer histopatolojik değişiklikler görülebildiğinden bu tür klinik bilginin belirtilmesi doğru tanıya ulaşılması ve ayırıcı tanının yapılabilmesi açısından önemli olmaktadır (11). Ürolojik tümör piyeslerinde patolojik materyalin nasıl gönderileceği ve değerlendirileceği konusunda bir kaynak olan "Ürolojik Tümörlerin Patolojik Değerlendirme Standartları ve Kılavuzları'"nda hem patologlara hem de ürologlara ayrıntılı öneriler yer almaktadır. Bu kılavuz ayrıca tüm diğer patoloji seksiyonları için de örnek teşkil etmektedir $(11,12)$.

Örnek gönderimi ile ilgili olarak çelişkide kalınan durumlarda Patoloji bölümü ile derhal iletişime geçilmeli ve örneğin hangi şartlarda muhafaza edilmesi gerektiği ile ilgili bilgi alınmalıdır. Herhangi bir aşamada hata meydana geldiğinde düzeltici-önleyici faaliyetler planlanmalıdır. Patoloji personeli tarafından red formlarının ve hata tespit tutanaklarının eksiksiz olarak doldurulması ve saklanması, hata spektrumunun belirlenmesi ve ileriye dönük hataların azaltılmasını sağlayabilir. Patoloji bölümünde bir hata söz konusu olduğunda tüm Patoloji personeli bu hatanın olası kaynağını ön görebilmeli ve hata ile ilgili olarak ilgili bölüm sorumlusuna bilgi verilmelidir. Bu süreçte vakit kaybetmeden, hatanın fark edildiği anda önleyici ve düzeltici faaliyette bulunulması hatanın yol açabileceği klinik durumların önüne geçilmesini sağlayacaktır.

Çalışmanın önemli bir bulgusu da gönderen birim kaynaklı hataların Patoloji kayıt birimi kaynaklı hataların iki katından fazla olmasıdır. Usubütün ve ark.'nın Türkiye'de Patoloji laboratuvarlarında personelin iş yükünü değerlendirdikleri kapsamlı çalışmada bir patoloji teknisyeninin yılda ortalama 6.200 blok, 11.500 preparat ve 1.000 immünohistokimyasal inceleme yaptığı ve eğitim hastanelerinde Patoloji laboratuvarlarının $\% 62,5^{\prime}$ inin aşırı yüklü çalıştığı belirtilmiştir (13). Ayrıca örnek gönderimi esnasında gönderen birimin neden olduğu hataların çözümü genellikle Patoloji personeli tarafından sağlanmaya çalışılmaktadır. Aşırı yüklü çalışan bir patoloji laboratuvarında bu durum, vakaların kaydı ve işleme konmasında aksaklıklara sebep olmaktadır.

Patoloji kayıt personelinin kayıt esnasında ve raporun iletiminde sürekli hasta ile birebir iletişim halinde olması psikolojik stres yükünün artmasına ve hata riskine yol açmaktadır. Klinikopatolojik toplantılar düzenlenerek bu konuların ele alınması düzgün ve verimli Patoloji işleyişinin sağlanmasında yararlı olacaktır.

\section{Sonuç}

Sağlık sektörü birlikte çalışan birimlerin sürekli koordinasyon halinde olmasını ve kalite standartlarına eksiksiz olarak uyulmasını gerektirir. Patolojik incelemenin gerekli olduğu durumlarda gönderimi yapan birimlerde genellikle alınan dokunun hızlı bir şekilde Patoloji laboratuvarına transferi hedeflenmektedir. Aynı şekilde Patoloji laboratuvarına materyal geldiğinde kayıt personelleri de örneklerin yine hızı ıir şekilde makroskopi laboratuvarına gönderilmesini sağlamaya çalışmaktadır. Bütün aşamalarda bu işlemlerin hızlı yapılması kadar doğru yapılması da hayati önem taşımaktadır. Bu nedenle biyopsiyi alan hekim başta olmak üzere tüm yardımcı sağlık personelinin örnek gönderimi, kabul ve red kriterleri hakkında bilgi sahibi olması ve personellerin rotasyonu söz konusu olabildiğinden sürekli eğitim verilmesi gereklidir. 


\section{Kaynaklar}

1. TSE EN ISO 15189:2012 TEI. Tıbbi Laboratuvarlar --Kalite ve Yeterlilik için Şartlar. Erişim: http://www.kaliterehberi.com.tr/

2. Satılmış ÖK, Macit Y, Serteser M, Ünsal ì. Tıbbi Laboratuvarda Preanalitik Hatalar --Örnek Alımı. Sağ Perf Kal Derg 2015;9:19-26. Erişim: https://dergipark.org.tr/download/article-file/303480

3. http://www.turkpath.org.tr/files/EK\%201-7 -Dp.

4. http://www.turkpath.org.tr/upload/content/files/TIBBI_PATOLOJI_ LABORATUVARI_ORNEK_KABULU_SIRASINDA_DIKKAT_EDILECEK_ KONULAR_VE_RED_KRITERLERI.pdf.

5. Wiwanitkit V. Types and frequency of preanalytical mistakes in the first Thai ISO 9002:1994 certified clinical laboratory, a 6-month monitoring. BMC Clin Pathol 2001;1:5. [CrossRef]

6. Nakhleh RE, Idowu MO, Souers RJ, Meier FA, Bekeris LG. Mislabeling of cases, specimens, blocks, and slides: a college of american pathologists study of 136 institutions. Arch Pathol Lab Med 2011;135:969-74. [CrossRef]

7. Nakhleh RE, Zarbo RJ. Surgical pathology specimen identification and accessioning: A College of American Pathologists Q-Probes Study of 1,004,115 cases from 417 institutions. Arch Pathol Lab Med 1996;120:227-33.
8. Sinici Lay I, Pinar A, Akbiyik F. Classification of reasons for rejection of biological specimens based on pre-preanalytical processes to identify quality indicators at a university hospital clinical laboratory in Turkey. Clin Biochem 2014;47:1002-5. [CrossRef]

9. Fabbretti G. Risk management: correct patient and specimen identification in a surgical pathology laboratory. The experience of Infermi Hospital, Rimini, Italy. Pathologica 2010;102:96-101.

10. Yörükoğlu K. Quality Assurance in Pathology Laboratories. Aegean Pathology J (APJ) 2005;2:86-97. Erişim: http://www.turkjpath.org/ pdf/pdf_APJ_687.pdf

11. Behzatoğlu K. TURM materyali patolojiye nasıl gönderilmelidir? Patoloğun yaşadığı sorunlar ve çözümleri. Bull Urooncol 2009;2:5960. Erişim: http://cms.galenos.com.tr/Uploads/Article_8446/59-60. pdf

12. Üroonkoloji Derneği, Üropatoloji Çalışma Grubu. Ürolojik Tümörlerin Patolojik Değerlendirme Standartları ve Kılavuzları; 2010. Erişim: http://www.uroonkoloji.org/files/uroonkoloji.pdf

13. Usubütün A, Uner S, Harorlu F, Ozer E, Tuzlali S, Ruacan A, et al. Pathology laboratories staff workload evaluation in Turkey: a survey study. Türk Patoloji Derg 2011;27:98-105. [CrossRef] 